\title{
A EDUCAÇÃO SUPERIOR E A “INCLUSÃO SOCIAL": A RAZÃO DAS COTAS
}

\section{L'individualité, la différence et l'inégalité : la raison du systéme des quotas pour assurer l'acèss à l'enseignement supérieur au Brésil}

Lindomar Wessler Boneti ${ }^{1}$

\section{Resumo}

O texto tem como objetivo analisar as razões da necessidade do sistema de cotas para garantir o acesso ao ensino superior por parte de alguns grupos sociais. A questão fundamental analisada neste texto é a de compreender as razões do distanciamento de alguns segmentos sociais do ensino superior, as razões que levam à obstrução dos caminhos de acesso destes segmentos a este tipo de ensino. Argumenta-se, neste texto, que a necessidade da institucionalização de cotas para garantir o acesso de certos grupos sociais ao ensino superior transcende à problemática criada pela limitação de vagas nas instituições públicas e pelas dificuldades financeiras das pessoas para 0 pagamento das instituições particulares. A questão é mais complexa, a perspectiva da homogeneidade e do antidiferencialismo praticada pelo sistema de ensino superior, quer seja pela instituição pública ou privada, constitui-se também de uma razão do acesso negado a certos grupos sociais. Palavras-chave: Desigualdades Sociais; Educação Superior; Sistema de Cotas.

\section{Résumé}

Le texte a comme sujet l' analyse des raisons de la nécessité du système des quotas pour assurer l' acèss à l' enseignement supérieur de cartains groupes sociaux. La question fondamentale analysée dans ce texte est de compreendre les raisons de l' éloignement de quelques segments sociaux de l' enseignement súperieur, les raisons qui amènent à l' obstruction des chemins $\mathrm{d}$ ' acèss de ces segments à ce type $\mathrm{d}^{\prime}$ enseignement. On argumente, dans le texte, que la

1 Prof. Dr. do Programa de Pós-Graduação da PUCPR - Mestrado em Educação.

E-mail: boneti@rla01.pucpr.br 
nécessité de l' institutionnalisation des quotas pour assurer l' acèss de certains groupes sociaux à l' enseignement supérieur transcende à la problematisation crée par la limitation des places dans les institutions publiques et par les difficultés financières des personnes pourle paiement des institutions privées. La question est plus complèxe, la perspective de l' homogénéité et de l' antidifférenciation pratiqué par le système de l' enseignement supérieur, par l' institution publique ou privée, se fait aussi par la raison de l' acèss nié à certains groupes sociaux.

Mots-clé: Inégalité sociale; Enseignement supérieur; Système de quotas

Este texto tem como objetivo analisar as razões fundamentais da necessidade de uma sociedade instituir um mecanismo burocrático e legal (sistema de cotas) para garantir o acesso ao ensino superior por parte de alguns grupos sociais. A questão fundamental analisada neste texto não diz respeito às justificativas em si, para o sistema de cotas, ou de questioná-las, uma vez que a problemática social em si justifica tal sistema. A questão que se coloca é compreender as razões do distanciamento de alguns segmentos sociais do ensino superior, as razões que levam à obstrução dos caminhos de acesso destes segmentos a este tipo de ensino. Busca-se, na análise que aqui se faz, superar o simplismo de associar a questão em apresso à simples limitação de vagas em instituições públicas e às dificuldade financeiras de pagamento de instituições privadas por parte das pessoas impedidas do acesso ao ensino superior. Argumenta-se, neste texto, que a necessidade da institucionalização de cotas para garantir o acesso de certos grupos sociais ao ensino superior transcende à problemática criada pela limitação de vagas nas instituições públicas e pelas dificuldades financeiras das pessoas para o pagamento das instituições particulares, considerando que este argumento não chega à essência da questão analisada. Algo mais, como a perspectiva da homogeneidade e do antidiferencialismo, característica própria do racionalismo científico adotado pelas instituições de ensino superior, quer seja a instituição pública ou privada, constitui-se também de uma razão do acesso negado a certos grupos sociais ao ensino superior.

Para analisar a questão já exposta, necessário se faz iniciar pela caracterização dos grupos sociais que normalmente não têm acesso ao ensino superior, estes que são considerados os "diferentes" pelo convencionalismo social, os pobres, os negros, os índios, enfim, os grupos sociais que melhor sentem as desigualdades sociais. A questão que se coloca inicialmente é se estes grupos são mesmo os considerados "os desiguais" e de qual parâmetro utilizado parte-se para assim considerá-los. Necessário se faz, portanto, identificar, inicialmente, a construção social da noção da igualdade ou da desigualdade, quem são os iguais e os desiguais ou quem são os "diferentes". 


\section{A construção e o caráter da noção da igualdade e da desigualdade}

O conceito de "minoria", dos grupos "minoritários" ou ainda dos "diferentes", para os quais institucionaliza-se o sistema de cotas para garantir o ingresso ao ensino superior, está assentado sobre a noção dicotômica do "igual"/ "desigual". Mas quem são os "iguais" e os "desiguais" e como se chega a esta diferenciação? É necessário compreender os critérios utilizados, pela população em geral e pelas instituições, para designar o igual e o desigual numa sociedade de classe.

Na perspectiva de se compreender a construção social da noção da desigualdade, realizou-se uma pesquisa, cujos resultados já foram publicados por Boneti (2000), utilizando-se a categoria pobreza. Alguns dados desta pesquisa contribuem para responder a questão principal analisada neste texto.

Os indicadores convencionais utilizados para a efetivação do cálculo da diferenciação social no Brasil são praticamente os mesmos utilizados por outras organizações mundiais, ou seja: saúde, educação e renda familiar. Mas na pesquisa citada observa-se que a categoria social considerada pobre não utiliza os mesmos critérios de delimitação da condição social utilizados pelas instituições públicas e pela classe social média e alta, ou seja, os que pressupõem resultados: rendimento mínimo, mortalidade mínima, analfabetismo mínimo, esperança de vida, capacidade de consumo etc. Os indicadores utilizados pela população considerada pobre são fundamentados sobre o acesso: ao trabalho, à educação, aos serviços de saúde etc. As instituições públicas não consideram a condição de acesso que a população tem a este serviço, utilizam apenas o resultado final de cada serviço essencial. De igual forma a renda para o segmento pobre da população entrevistada não tem importância, o importante é ter acesso a algum tipo de atividade que lhe renda qualquer coisa para ganhar a vida.

O primeiro aspecto constatado em relação à questão do ser pobre é que se tem uma diferença fundamental no discurso referente ao ser pobre, dependendo da condição social do entrevistado. As pessoas entrevistadas situadas em uma melhor condição de vida, fora da condição de pobreza, especialmente as pessoas mais escolarizadas, como é o caso de professores, estudantes de pós-graduação, médicos, advogados, engenheiros, comerciantes etc., demonstram a tendência de analisar a pobreza em todos os seus aspectos, utilizando como parâmetros mais ou menos semelhante aqueles utilizados pelas instituições públicas. Este segmento da população entrevistada utiliza parâmetros quantitativos e os da sobrevivência física, como é o caso do rendimento mínimo, como parâmetro de pobreza. Por exemplo, ser pobre é não ter o que comer, ser analfabeto, não ter moradia, viver na condição de higiene precária etc. Outro aspecto muito citado por este grupo de entrevistados é o 
poder de compra: o poder de aquisição, a compra de roupas, de brinquedos para as crianças. Isto é, a "cultura do consumo" aparece como parâmetro de delimitação da condição social para este segmento social entrevistado.

Outro aspecto levantado por este grupo de pessoas, sobretudo entre os entrevistados da região Sul do Brasil, mais especificamente pessoas ligadas a atividades do tipo comerciantes, profissionais liberais etc., utilizar como parâmetro de pobreza critérios subjetivos, valores e questões morais, como é o caso de ter objetivos de vida, associando a condição de pobre a não objetivação da vida.

Na realidade, estas pessoas entrevistadas, citadas acima, utilizam um novo critério de definição da pobreza que aparece cotidianamente no discurso popular, uma narrativa que consolida uma maneira de ver de uma parte da população não pobre. Trata-se de considerar que existe uma "cultura" própria das pessoas pobres, uma "racionalidade" de pobre, diferente da homogeneidade racional dominante da população em melhores condições sociais.

Outro parâmetro utilizado para considerar uma pessoa pobre, citado pelas pessoas consideradas pobres, paralelamente ao acesso, diz respeito ao fato de não ter ocupação, mesmo que esta ocupação seja informal e de rendimento mínimo. Neste caso atribui-se à pobreza um importante significado, 0 da não utilidade social, comprometendo com isto a identidade social das pessoas. Dizendo inversamente, seriam pobres as pessoas que não teriam identidade social por não se sentir útil na sociedade. Ou seja, para as pessoas pobres, uma atividade social, mesmo que tenha uma valorização simbólica mínima para a sociedade, retira a condição de pobre das pessoas. Em geral, as pessoas consideradas pobres a partir dos parâmetros utilizados pelas instituições oficiais, com exceção das pessoas que se encontram na condição de indigente, que vivem de ajudas, não se consideram pobres quando têm uma ocupação. Mesmo as pessoas que vivem de um rendimento mínimo ou que vivem de uma atividade informal, como é o caso dos "flanelinhas", estes não se consideram pobres porque vigiar e lavar automóvel é uma atividade, é ter o que fazer, é sobreviver. Estas pessoas utilizam como parâmetro o fato de se sentir úteis, de ter uma ocupação. Isto significa que o conceito de trabalho para as pessoas pobres é diferente do conceito dominante, acentuando na importância do fato de se ter o que fazer e garantir o sustento, relativizando a importância de ser formal ou informal.

Os dados da pesquisa relativos à origem em si da pobreza é outra questão que merece destaque. O segmento da população entrevistada que não pertencente à condição de pobre se divide no que se refere à análise desta questão. Geralmente as pessoas que se dizem mais politizadas, como é o caso dos professores, dos estudantes de pós-graduação etc., consideram unicamente 0 modelo econômico em vigor no país e o desemprego como 
origem da pobreza. Mas as pessoas qualificadas que têm uma atividade profissional um pouco distantes das discussões acadêmicas, como é o caso dos comerciantes, dos profissionais liberais etc., apelam à "racionalidade" ou a existência de uma "cultura" de pobre da qual já fizemos referência neste texto. Para estas pessoas, o modelo econômico seria um fator importante, mas 0 mais importante ainda é a vontade de vencer, ter um objetivo concreto na vida, vontade de trabalhar, de lutar.

Como interpretar esta diferença entre um e outro segmento social no que se refere à delimitação da condição social e o que isto tem a ver com a temática analisada neste texto?

Observa-se que os parâmetros de determinação da condição social utilizados pelas instituições e pelas pessoas pertencentes à classe média e alta guardam determinações valorativas vinculadas a bens reais ou simbólicos normalmente de posse das classes dominantes, como é o caso de habilidades técnicas, hábitos culturais, capacidade de consumo etc. e que isto dá ao segmento pobre da população uma condição de ser e não de estar pobre. Isto seria dizer que a pobreza teria origem e é explicada pela existência de uma "racionalidade" de pobre. Na prática os parâmetros que partem dos resultados e não do processo suplantam habilidades e demais bens sociais que caracterizam posse dos segmentos pobres e com isso faz com que o pobre se transforme mais pobre pela condição de ser que a ele é atribuída, no lugar da condição de estar.

Conclui-se, portanto, que a construção da condição social elaborada a partir de parâmetros racionalistas e cientificistas de instâncias burocráticas do Estado se materializa, no meio social, pela construção de identidades coletivas, aos moldes como Manuel Castells, (1999, p.22-25) pensa. Ou seja, a instância burocrática do Estado poderia determinar a construção da condição social por meio do que este autor chama de 'identidade legitimadora', introduzida pelas instituições dominantes da sociedade, no intuito de expandir e racionalizar sua dominação em relação aos atores sociais...". Isto explica o fato de que alguns segmentos sociais, como as classes médias e altas, utilizam os mesmos parâmetros de delimitação da condição social daqueles utilizados pelas instituições públicas. Além desta "identidade legitimadora" da qual fizemos referência, podemos considerar que a utilização de critérios racionalistas e etnocêntricos por alguns segmentos sociais na delimitação da condição social igual aqueles utilizados pelas instâncias burocráticas do Estado tem origem também na construção histórica de uma racionalidade capitalista, muito própria do mundo Ocidental, aquela teorizada por Max Weber, que dá fundamentos a uma construção imaginária e até cultural da condição social fundamentada numa razão instrumental.

Na prática, no meio social, existe uma mistura de imaginário e reali- 
dade na construção da noção da desigualdade normalmente envolvendo diferentes conceitos que se entrelaçam, como é o caso do da condição social com o da diferença. Pensar sobre desigualdade implica pensar a condição social; pensar sobre a condição social implica pensar sobre diferença. A diferença aparece sempre como uma espécie de parâmetro de determinação da condição. A diferença explicita aquela condição social, aquele comportamento, aquele modo de produção da vida etc. que foge ao padrão convencional. Portanto, a noção de diferença, como aparece nos dados analisados, e que não se distancia da noção praticada na academia, apesar de se constituir num instrumento de determinação da desigualdade, é vista de uma forma positiva enquanto que a noção da desigualdade aparece sempre com conotação negativa.

A negatividade imbuída na noção da desigualdade nasce dos parâmetros que se estabelecem para determinar uma condição social julgada "digna" para o sujeito social. Neste caso, a desigualdade estaria associada a uma condição social dita inferior, o desigual seria o pobre e não o rico, o diferente seria 0 pobre e não o rico, mesmo que o pobre se apresente na maioria. A diferença entre um e outro sujeito social acaba sendo associada, tanto pelo imaginánio social quanto pelas instituições públicas, com o ser do sujeito em lugar do estar. Isto é, deixa de ser uma condição passageira do sujeito social para se constituir numa condição perene, ou até numa qualidade ou numa racionalidade.

Esta construção social da noção da desigualdade faz dos iguais os desiguais. Por exemplo, pessoas humildes que se vestem iguais, que igualmente todos têm aperto no orçamento, com uma condição social similar, tornam-se diferentes se comparar com uma pessoa que tem hábitos luxuosos de consumo, que se veste diferentemente de todos, esta se torna ela sozinha a igual, porque o padrão dela é o utilizado pelo conjunto social como referencial para se estabelecer parâmetros de definição da condição social, pelo fato de ser acolhido pela racionalidade burguesa. Os demais, mesmo em maioria, se tornam, perante ela, os desiguais. Por quê? Porque a igualdade não se estabelece pela maioria, mas a partir do conceito do padrão, que na nossa sociedade capitalista é imposta pelas classes dominantes. O igual assume uma posição de comando, para não dizer dominador ou no mínimo de superioridade, perante o diferente.

Em outras palavras, a desigualdade, além de ter origem nas relações da vida real, estabelece parâmetros de delimitação da condição social envolvendo relações de dominação, que faz florescer ainda mais a desigualdade. Portanto, existe uma relação de dominação até mesmo na utilização dos parâmetros para delimitar as condições sociais.

Estes parâmetros partem de critérios valorativos envolvendo habilidades, bens reais, culturais e simbólicos normalmente em poder de segmentos sociais dominantes. 
Trata-se, portanto, de uma noção de desigualdade assentada sobre a capacidade individual do acesso ao capital social e cultural. Este é o fundamento da adoção do estigma de "grupos minoritários" (que em geral são maioria) ou dos "diferentes". Esta mesma lógica é utilizada na definição do conceito de ciência e do conhecimento científico, elementos estes que compõem o fim último da existência do ensino superior.

\section{A Dimensão Ideológica do Conhecimento}

Dois aspectos são importantes para começar pensar o significado do conhecimento técnico e a dimensão complicativa do seu repasse a todos os segmentos sociais. O primeiro aspecto diz respeito ao caráter ideológico da ciência e da técnica. Neste aspecto, optamos por nos valer da contribuição de Habermas (1973). Este pensador, na tentativa de recuperar o conceito de racionalidade a distanciando da simplória lógica instrumental (como, segundo Habermas, o positivismo clássico a transformou), mostra o lado relativo e ideológico e a dimensão não neutra do conhecimento técnico. E Brandão (1984, p. 46) contribui com a explicação do comprometimento ideológico do conhecimento ao dizer que o "triunfo atual da ciência levou-a a arrancar a máscara da neutralidade - empunhada principalmente pelos acadêmicos - e o disfarce de objetividade com que se pretende impressionar o grande público". O segundo aspecto a considerar está diretamente associado ao primeiro. A ciência se desenvolveu, historicamente, conjugada à expansão das atividades econômicas, e neste caso o progresso técnico assumiu um caráter ideológico de racionalidade. Assim, o caráter ideológico do progresso técnico é perfeitamente percebível ao se associar o conceito de racionalidade à forma capitalista da atividade econômica, entendendo-a como um conjunto de procedimentos visando a um fim econômico. A partir desta concepção, a racionalização não apenas consiste na escolha adequada das tecnologias e demais estratégias para transformação dos sistemas econômicos, mas a racionalidade significa adotar procedimentos tecnológicos e metodológicos de dominação. Dominação em duas principais instâncias: sobre a natureza e sobre o conjunto das relações sociais. A racionalidade, pela técnica, subtende controlar o meio natural e o meio social para extrair destas o máximo possível de lucro. Na sociedade capitalista o saber técnico é um bem de capital. O segmento social (grupo ou classe) que dispõe do saber e do instrumental tecnológico tem poder de dominação e de controle sobre a natureza e sobre as relações de produção. Mesmo quando o Estado fomenta o desenvolvimento tecnológico, ele o faz lançando um processo de competitividade e/ou seletividade entre os sujeitos sociais e/ ou grupos sociais. Isto porque o Estado parte do pressuposto 
de que os segmentos sociais são homogêneos e impõe uma homogeneidade como padrão de racionalidade. Por exemplo, a racionalidade de um camponês é diferente de um técnico agrícola. Estes dois sujeitos têm acesso ao progresso tecnológico em condições diferenciadas. A racionalidade do técnico, evidentemente, aproxima-se mais do padrão homogêneo exigido pela política de fomente tecnológico.

Nesta dimensão, "o conceito de verdade deixa de ser uma qualidade fixa, sendo condicionado por uma função de poder que formaliza e justifica 0 que é aceitável. E essa aceitação é condicionada a visões concretas da sociedade política e seu desenvolvimento" (Brandão, 1984, p. 47).

Neste caso, o controlar e o dominar as relações sociais de produção e a natureza assume um papel excludente. A lógica da substituição dos fatores de produção, empregada pelas teorias da modernização, exclui o homem, (e seu trabalho) seus hábitos culturais e os ciclos naturais. A técnica é superior e é colocada acima do natural, ela tem poder de dominar o natural. É nesta lógica em que podemos situar a devastação do meio natural, uma lógica não de inclusão, mas de dominação e exclusão. No âmbito das relações de produção, a técnica é utilizada como fator de dominação das relações de produção e, enquanto tal, na situação progresso tecnológico ela não absorve as diferenças, mas as exclui.

Portanto, as instituições de ensino superior não operam com conhecimento neutro tampouco com conhecimento com características singulares e produzidos por segmentos sociais também considerados "singulares".

\section{A Ciência e os fundamentos da instituição de ensino superior}

Os fundamentos das instituições de ensino superior têm origem numa racionalidade científica e econômica, e assim é normal que esta instituição mantenha neutralidade em relação às emoções, aos desejos e aos conflitos sociais. O pensamento que move a instituição de ensino superior é o pensamento tipicamente burguês, construído historicamente e concomitantemente ao aparecimento das bases ideológicas do capitalismo, e que coincide com o que se entende como pensamento científico hoje. Em outras palavras, o desenvolvimento histórico do pensamento científico coincide com o desenvolvimento do capitalismo, cujos principais ingredientes compõem a razão deste tipo de instituição. Trata-se de pensamento construído com a incorporação de ingredientes originados nas ciências da natureza.

Com o aparecimento do método experimental e o avanço da ciência do domínio da natureza, a física parece ser o primeiro ingrediente a se integrar no processo da formação das ciências humanas. A economia política foi cons- 
tituída na Inglaterra no decorrer da Revolução Industrial e da glória de Newton, quando se tinha uma influência considerável da epistemologia positivista. A partir de então, grandes teóricos das ciências do desenvolvimento econômico, como Adam Smith, Walras, Pareto e Saint-Simon desejavam ser o Newton da mecânica social da produção e do consumo de riquezas (Grinevald, 1975, p. 40). A idéia que associa o progresso da humanidade à força e à energia pode ter sua origem na física, particularmente na termodinâmica. Em síntese, o pensamento de Newton cruzou as fronteiras do mundo natural para o social. Assim, Saint-Simon, um dos precursores da ciência humanas, foi um dos primeiros teóricos a associar o progresso humano à idéia da força e da energia. Esta interpretação dava origem não apenas à idéia segundo a qual o desenvolvimento social está condicionado ao desenvolvimento industrial (o sinônimo do capitalismo), mas a que não existe singularidade no que se refere ao desenvolvimento social. Trocando em miúdos, o aparecimento da combustão deu origem a um mecanismo (o motor) do qual depende o movimento da composição do sistema industrial. Como o da indústria, a força que impulsiona o desenvolvimento não nasce do mesmo corpo (comunidade, por exemplo), mas de uma força externa. É o mesmo que dizer que existe um centro no qual as idéias dito científicas se encontram e dele nascem e impõem um padrão homogêneo a partir do qual devem se adaptar as singularidades. Isto é mesmo que dizer que comunidades ou pessoas que utilizam modelos singulares de produção jamais podem se desenvolver socialmente a partir das suas próprias experiências, mas dependem de idéias e tecnologias externas. Assim como as idéias e costumes singulares têm dificuldades de encontrar espaços no mundo convencional. Tais premissas fundamentaram as teorias da modernização, particularmente a teoria do capital humano de Theodore Schultz, segundo a qual o processo educativo se constitui, antes de tudo, de mudanças de hábitos, comportamentos etc., absorvendo-os de outros contextos. Mas na instituição de ensino esta premissa se faz presente na medida em que se institui um modelo correto de saber e de comportamento.

A idéia do movimento, por outro lado, se constitui em outro fator importante na sociedade humana durante o período da modernidade. A idéia do movimento se constitui até em parâmetro para distinguir o normal e 0 anormal da vida de uma pessoa ou de uma sociedade. A idéia do movimento, que pode ter origem da termodinâmica, dá conta que o indivíduo (ou a sociedade) em plena faculdade de normalidade esteja permanentemente em movimento, no que se refere à acumulação de riquezas, acumulação de saberes e que isto designa melhorias de condições de vida. Em outras palavras, isto se chama progresso que na modernidade assume um caráter ideológico que garante as bases da própria modernidade. Nas atuais instituições de ensino, a marca do progresso se encontra em inúmeras características de tais institui- 
ções, mas, sobretudo, na lógica da progressão. A progressão tem apenas 0 significado da seriação, mas sustenta o caráter ideológico que garante a superioridade social do conhecimento científico.

Outro aspecto a considerar é o caráter universalista da razão. Isto é, o de que existe um saber único verdadeiro, um padrão cultural e comportamental único verdadeiro etc., aparecendo com maior nitidez a concepção etnocêntrica, tendo como ponto de partida o racionalismo científico. As idéias de Augusto Comte, por exemplo, expressam a preocupação da universalização de um padrão tecnológico e a vulgarização de um saber clássico e universal. Isto é, aparece aqui além de uma concepção universalista da razão, aquilo que Rousseau criticava: a concepção etnocêntrica. Em outras palavras, a verdade é uma só, ela é universal e está no centro. No dia-a-dia da instituição de ensino este pensamento aparece, sobretudo, na atribuição de um saber correto e outros errados.

A infalibilidade do conhecimento científico também fundamenta a razão da instituição de ensino superior. A técnica, por ser fruto da ciência, é infalível e a sua universalização é automática, levada pelas relações econômicas. Saint-Simon dizia que a industrialização da sociedade se inscreve no contexto daquilo que ele chamava de "lei superior do progresso" que se impõe, quer os homens queiram ou não. Os homens não são nada mais dessa lei que seus instrumentos. Segundo Saint-Simon, esta "lei superior do progresso" deriva de nós, mas não está mais sob o nosso controle, não se tem mais condições de controlar a sua ação. Tudo o que se pode fazer é obedecer esta lei, prestando atenção à sua marcha (ANSART, 1979).

A razão instrumental, que atende os requisitos da expansão da produção econômica, está na concepção, historicamente construída, de considerar conhecimento científico aquele que é útil. Na era do iluminismo este preceito já existia e pode ser a raiz da associação que se faz da instituição de ensino e 0 atendimento das demandas da produção material.

Portanto, a razão da instituição de ensino é fundamentada sobre a produção do conhecimento universal (somente o universal, que pode e deve ser universal), a partir do qual produz-se a técnica a qual passa a possuir um caráter de infalibilidade e esta associa o conhecimento à utilidade.

A absorção do conhecimento, quer seja por meio da instituição de ensino ou no contexto social, assume um caráter ideológico de progressão (com contaminações evolucionistas). Isto é, a idéia da progressão na absorção do conhecimento constitui-se de um dos principais elementos da racionalidade dominante. Esta noção se constitui de um caráter ideológico porque exige que o sujeito social acredite que a escola lhe fará absorver, progressivamente, o conhecimento dominantemente requerido pelo contexto social. Ou seja, a escola lhe fará apropriar-se de um capital social valorizado. 
Se consultarmos os clássicos que discutem o papel das instituições de ensino em geral, concluiremos que desde a instauração da era da modernidade a instituição escolar assumiu para si o papel da construção de uma racionalidade burguesa. Durkheim (1978), representante do positivismo clássico, numa perspectiva consensual, ao realçar o papel da instituição de ensino como o de garantir a continuidade da vida material e social, tanto do ponto de vista da transmissão da cultura como a da preparação de habilidades necessárias, não se difere significativamente de pensadores representantes de uma linha crítica, como é o caso da reprodução da cultura dos mecanismos de perpetuação do monopólio da classe dominante sobre as demais para Bourdieu (2001) assim como para Marx, enquanto instituições de reprodução da ideologia dominante.

Nos dias de hoje, insere-se no contexto da dinâmica da globalização da cultura e das relações econômicas, traços ideológicos que atendem a uma racionalidade técnica e instrumental, muito própria e propícia do modelo capitalista vigente. A ciência se desenvolve de forma conjugada à expansão das atividades econômicas, e neste caso o progresso técnico assume um caráter ideológico de racionalidade. O caráter ideológico do progresso técnico é perfeitamente perceptível ao se associar o conceito de racionalidade à forma capitalista de atividade econômica,

entendendo-a como um conjunto de procedimentos visando um fim econômico. A partir desta concepção, a racionalidade não apenas consiste na escolha adequada das tecnologias e demais estratégias para transformação dos sistemas econômicos, mas a racionalidade significa também a adoção de procedimentos tecnológicos e metodológicos de dominação (BONETTI, 2002, p.225).

Dominação esta sobre a natureza e sobre o conjunto das relações sociais. A racionalidade por meio da técnica subtende controlar o meio natural e o meio social para extrair destes o máximo possível de lucro. Em outras palavras, exige-se da escola a construção de habilidades de competitividades e até mesmo de construção de poder na busca da acumulação de capital e na busca da acumulação de saberes tecnológicos. Isto significa dizer que o papel da instituição de ensino de construção de uma racionalidade burguesa se resume hoje no instrumentalismo, que se adquire com a progressão.

\section{Considerações finais}

Na medida em que a instituição de ensino superior assumiu historicamente o compromisso com a racionalidade científica associada ao desenvolvimento econômico, construiu afinidades com as classes dominantes distancian- 
do-se dos demais grupos sociais não "homogêneos", os ditos "diferentes". Este caráter formado pela triologia "ciência", "racionalidade burguesa" e "desenvolvimento econômico" propiciou a abertura de um vácuo entre a razão individual e suas complexas condições sociais, como as de classe e as étnicas, e a razão institucional da instituição de ensino. Isto é, trata-se de pensar a questão buscando compreender a complexidade inerente às condições sociais de diferentes segmentos sociais ou classes e a lógica (pensamento racional) da instituição de ensino. Isto faz com que a problemática de distanciamento do ensino superior com alguns segmentos sociais não se situe apenas na dualidade entre o caráter mercadológico deste ensino e a condição social das pessoas, mas também no nível da diferenciação entre o caráter individual do sujeito com o caráter social do institucional. Ou seja, existe um vácuo entre 0 individual, (onde nasce a aspiração, a emoção, a espontaneidade e a condição social) e o social, onde situa-se a ação formal e racional. Na Idade Média existia uma afinidade triangular, a razão individual, a monástica e a nascente razão científica iluminista. Com a instauração da modernidade, esta afinidade estreitou-se e se tornou dual, entre o individual e o coletivo, na medida em que o racionalismo incorporou ingredientes originados da filosofia monástica, muito fortemente presente em algumas correntes filosóficas, como a de Kant, traduzindo-se o racional pelo domínio da natureza fraca e das vontades e a instauração de uma disciplina comportamental. Nos dias atuais, este racionalismo científico, aliado a estes ingredientes monásticos (estudar como ato de sofrimento e disciplina, cumprimento de horários e obediência), compõe 0 caráter da razão da instituição de ensino, mas não dos indivíduos que a freqüentam. Criou-se este vácuo porque na modernidade tornou-se importante 0 papel social coletivo, dissolvendo-se o indivíduo na classe social, no grupo ou nos próprios papéis exercidos. Se na Idade Média o ser sujeito confundia-se com o caráter do ser de alguém, do pertencimento, na modernidade o ser sujeito passa a ser identificado no conjunto do coletivo, tanto do ponto de vista da classe (ou grupo), como no ponto de vista da função social. O caráter do papel social passou a se misturar com o da organização profissional.

O contexto social e político em que as instituições de ensino superior estão inseridas se constitui de uma ordem vigente, uma ordem legal, econômica e social, que se diz representante da racionalidade. Esta ordem se diz portadora da racionalidade pelo fato de agir de conformidade com parâmetros convencionais regidos pelos rigores ditos científicos, como é o caso da técnica. Centrada na idéia da racionalidade única e universal, para esta ordem a diferença é, no mínimo indiferente, ou ainda, inconveniente. A tentativa da ordem do poder nunca é a do reconhecimento da diferença como a relativização da verdade, mas sempre a de considerar o fora para integrá-lo ao dentro, quando é possível, quando isto não signifique perigo à ordem vigente. 


\section{Referências}

ANSART, Pierre. Sociologie de Sant-Simon. Paris: Presses Universitaires de France, 1970.

BONETI, LindomarW. Construction sociale de la notion de pauvreté au Brésil.. In: CONGRÈS DE L 'AISLF: ASSOCIATION INTERNACTIONALE DES SOCIOLOGUES DE LANGUE FRANÇAISE: GROUP DE TRAVAIL INÉGALITÉS, IDENTITÉS ET LIENS SOCIAUX. 16., Anales... 2000. (Atas do Congresso).

BONETI, LindomarW. Políticas Públicas, Educação e Exclusão Social. In:

. (Org.). Educação, ex clusão e cidadania. 3. ed. Ijuí: Unijuí, 2002. p. 13-38.

. As Políticas educacionais, a gestão da escola e a exclusão social. In: . (Org.). Gestão da Educação: impasses, perspectivas e compromissos. 3. ed. São Paulo, SP: Cortez, 2002.

BOURDIEU, Pierre. A economia das trocas simbólicas. São Paulo, SP: Perspectiva, 2001.

CASTELLS, Manuel. $O$ poder da identidade. São Paulo, SP: Paz e Terra, 1999. DURKHEIM, Ėmile. Educação e sociologia. São Paulo, SP: Moelhoramentos, 1978.

GRINEVALD, J. Science et développement: esquisse d'une approche socioépistémologique. In: _ La pluralité des mondes: Cahier de l'I.E.D. 1. Genebra e Paris: P. U. F, 1975. p. 40-65.

ROUSSEAU, Jean-Jacques. Discurso sobre a origem e os fundamentos da desigualdade entre os homens. In: . Rousseau. São Paulo, SP: Nova Cultural, 1991. p. 201-320. (Coleção os Pensadores, n. 6). 